\title{
O QUE ACONTECEU NA AULA? Políticas, currículos e escritas nos cotidianos da formação de professores numa universidade pública
}

\author{
Maria Luiza Süssekind Veríssimo ${ }^{(*)}$
}

\section{OS PORQUÊS E COMO...}

No período de cerca de 20 anos, entre o fim da ditadura civil-militar, marcado pela constituição de 1988/LDB/1996 e o golpe jurídico-político-midiático-legislativo de 2016/2017 o país experimentou políticas governamentais de democratização, estruturação, ampliação, interiorização e qualificação dos sistemas públicos de educação em todos os níveis e modalidades sendo estas políticas também voltadas para a inclusão, ampliação do acesso, democratização da permanência e valorização da própria ideia de educação pública laica democrática e de qualidade social. Se, por um lado, valorizamos estas conquistas, por outro, temos chamado atenção para o crescente domínio de um reformismo calcado não só na fé no potencial da ciência em resolver os problemas do mundo, mas também no poder que a educação teria de mudar as sociedades (AUTOR, 2014), e também, apoiado fortemente no que "Taubman (2009), em texto primoroso, chama de uma linguagem da pedagogia. Essa linguagem oferece, para o autor, o suporte técnico para que grande parte dos professores americanos apoie uma cultura da avaliação que lhes tira a autonomia e o controle sobre seu próprio trabalho" (MACEDO, 2016, p. 49).

Defendo que a Base (MEC, 2017, p. 18) resume, reitera e metaforiza essa linguagem além de nutrir as crenças correlatas e se apresentar hoje como política governamental oficial e central para a Educação Básica, na medida que propõe um sistema, uma

[P]olítica nacional da Educação Básica e vai contribuir para o alinhamento de outras políticas e ações, em âmbito federal, estadual e municipal, referentes à formação de professores, à avaliação, à elaboração de conteúdos educacionais e aos critérios para a oferta de infraestrutura adequada para o pleno desenvolvimento da educação. (MEC, 2017, p. 8)

\footnotetext{
${ }^{(*)}$ Licenciada em História pela Pontifícia Universidade Católica do Rio de Janeiro (PUC-Rio/1990). Mestre em Ciências pelo Centro de Pesquisa em Ciências, Desenvolvimento, Agricultura e Sociedade da Universidade Federal Rural do Rio de Janeiro (CPDA/UFRRJ-2002). Doutora em Educação pelo Programa de Pós-graduação em Educação da Universidade do Estado do Rio de Janeiro (ProPEd/UERJ-2007). E pós-doutora pela The University of British Columbia/UBC, Canadá, 2013. Atua como professora no Departamento de Didática e no Programa de Pós-Graduação em Educação na Universidade Federal do Estado do Rio de Janeiro (PPGEdu/UniRio). Coordena o Projeto de Pesquisa e formação Pibid/Interdisciplinar. É líder do Grupo de Pesquisa Práticas Educativas e Formação de Professores (GPPF). Vice e Coordenadora do GT de Currículos da Associação Nacional de Pós-graduação e Pesquisa em Educação (ANPEd), 2013-2017. Tem como focos de pesquisa: epistemologias, currículos, formação de professores e estudos do cotidiano. E-mail: luli551@hotmail.com.
} 
Com o objetivo de discutir não as políticas oficiais, marcadas como as grandes leis e decisões e seus atores e agências reconhecidos de modo generalizado nas teorias e no mundo, mas suas implicações em relação ao que acontece nas salas de aula, seguimos as pistas das escritas de estudantes numa turma de formação de professores. Numa abordagem epistemológica do Sul (SANTOS, 2007) e praticando uma sociologia das ausências (SANTOS, 2004), buscamos desinvisibilizar com o texto de um estudante algumas presenças negadas, silenciadas e produzidas como inexistentes em sua escrita errada.

Contextualizar o papel do uso da escrita correta no espaçotempo ${ }^{1}$ da universidade e da formação de professores como fluxos e políticas cotidianas, como práticas de poder (CERTEAU, 2012b, p. 125, 126) e imaginar que uma das preocupações centrais dos defensores da Base é a aquisição de habilidades de leitura e escrita (e nas idades certas) foi a premissa para enfrentarmos essa questão e esse artigo. Desconstruir a ideia de escrita boa e correta a partir do trabalho de fim de curso de um estudante pensando a língua como armadilha incestuosa para as articulações precárias nas criações curriculares cotidianas, me parece importante num momento de inundação de memes e disputas de sentidos que levam ao banimento de palavras, como advogam os desideologizadores das escolas. Nesses contextos reverberam as testagens externas e estandardizadas, manuais didáticos e politicas de unificação curricular. Penso ser oportuno tirar a palavra do centro do debate e valorizar "as táticas de consumo, engenhosidades do fraco para tirar partido do forte" (CERTEAU, 1994, p. 44) para “desembocar então em uma politização das práticas cotidianas" (idem). Argumento a seguir que as criações curriculares e as escritas são criações cotidianas e colorem ou maquiam as marcas políticas de/em nossos eus nos cotidianos. Proponho pensar as escritas como lugar da diferença, emaranhados de eus, histórias, contextos, desejos e por entender que merecem atenção maior diante de um contexto nacional e global de ameaça à democracia e à educação pública.

\section{"A ESCRITA PRA MIM NUNCA FOI UM LUGAR DE EMANCIPAÇÃO ${ }^{29}($ SIC)}

Mas onde o aparelho científico, o nosso, é levado a partilhar a ilusão de poderes de que é necessariamente solidário, isto é, a supor as multidões transformadas pelas conquistas e vitórias de uma produção expansionista, é sempre bom recordar que não se deve tomar os outros por idiotas. (CERTEAU, 1994, p. 273).

\footnotetext{
${ }^{1}$ Inserida no campo das pesquisas nosdoscom os cotidianos, nossa escrita emprega em muitos momentos a justaposição, escrita e estetização diferenciada de palavras a fim de buscar reinventar as palavras já que a língua[gem] prescrita não alcança acessos aos sentidos do vivido.

2 (EA, Turma de Currículo, 2017.1)
} 
É esse preenchimento contingente de um significante vazio por demandas particulares tornadas momentaneamente equivalentes que me interessa analisar, com o objetivo de entender as “articulações precárias [...] sempre ameaçadas por um exterior constitutivo" (LACLAU, 2000, p. 192) ou os discursos que se apresentam como resposta às crises de significação. (MACEDO, 2016, p. 48)

Não há um lar para onde retornar, não há possibilidade de congruência em relação a uma personalidade já formada, cunhada. O que alguém tem sido e é sempre contém o que não tem sido e não é. E o que foi rejeitado e reprimido define, ou pode definir, o self tão inteiramente quanto aquilo que aceita e integra conscientemente. A participação do self na personalidade, todo o processo e possibilidade sugeridos pelo imaginário de uma arquitetura do self, é a todo momento uma escolha política. (PINAR ${ }^{3}, 1994$, p. 212)

Estudar e escrever sobre o quanto a escrita é um exercício complicado e que mexe com os estudantes era para mim um desafio remoto até que resolvemos ler sobre isso com uma turma de formação de professores. Vimos que Certeau, em sua leitura de Foucault, sugere que a economia das práticas intelectuais desenvolveu maneiras próprias de praticar o poder. São elas, por exemplo, as práticas de linguagem, de espaço, de uso de tempo etc. que não são entendidos como um modo de ação que age sobre os outros, mas sobre a ação deles (CERTEAU, 2012b, p. 125, 126). Portanto, escrever seria uma ação que sofre o poder das políticas de escrita e que cria outras políticas de escrita.

Usamos a língua para escrever e dizer coisas que estão além da língua e mesmo da vida cotidiana. Contudo, "vivemos dominados por uma percepção redutora e utilitária que converte os idiomas num assunto técnico" (COUTO, 2011, p. 14.) e suas práticas em hierarquias, exclusão e invisibilização. Se as "línguas servem para comunicar" (COUTO, 2011, p. 13), e, às vezes, nos fazem "ser" (Idem), é preciso lutar pelo direito de que cada um traduza seus pensamentos em muitas e diferentes escritas, e se faça presente, já que no mundouniversidade "a palavra tem que lutar para não ser silêncio" (Ibidem).

Num momento de tratamento da linguagem como coisa pelos testes de larga escala padronizados e obsessão pelo aprendizado da norma e supervalorização da linguagem e da escrita nos documentos curriculares decidi operar para a "desconstrução do logocentrismo" (DERRIDÁ, 2014, p. 289). Não o presente nas Políticas mas nos cotidianos, inundados de praticantes das políticas. Nas aulas, temos lutado contra esse

\footnotetext{
${ }^{3}$ Tradução e grifo meus.
} 
sistema de repressão logocêntrica que se organizou para excluir ou abaixar por fora e embaixo, como metáfora didática e técnica, como matéria servil ou excremento, o corpo do traço escrito (DERRIDÁ, 2014, p. 291)

Argumento, a partir daí, que uma maneira interessante de pensar os centros de poder na academia é estudar os usos que fazemos das práticas e políticas de escrita... E, concluo que nossas escritas são sempre plenas de conhecimentos e autoconhecimento, e devem ser respeitadas pr'álem do uso da norma, ou com quaisquer usos (CERTEAU, 1994) da norma. Nossas escritas são escolhas, e por isso são escolhas políticas que se recheiam de nós mesmos. Nossa arquitetura de escrita traz nossos corpos, nossas marcas, nossas histórias, nossos selves. Escritas são, para mim, como narrativas de si, são selfies. O maquinário barulhento que embala estudantes sendo tomados como idiotas (sobretudo advindos das camadas mais pobres) porque se insinua contra a diferença numa "produção expansionista" (CERTEAU, 1994, p. 272, 273). Abalroa os sentidos precários que tentamos fixar em nossas escritas em nome das demandas do correto e do controle.

$\mathrm{Na}$ direção contrária, na universidade pública, vimos trabalhando em nosso grupo de pesquisa na busca de praticarpensar os currículos (OLIVEIRA, 2012) ao Sul em busca de situações de aprenderensinar que criem menos injustiça cognitiva. Justiça cognitiva é uma noção que aparece em Santos (2010) e sugere que a pluralidade e a coexistência de diferentes conhecimentos são emancipatórias e pautam a luta contra as injustiças dos sistemas colonial, patriarcal e capitalista que produzem epistemicídios no campo dos saberes. Essa pluralidade parte do reconhecimento da existência de conhecimentos vítimas dos epistemicídios cometidos pela hegemonia da Ciência e do Direito na Modernidade (SANTOS, 2010) globalizante. A língua, e seus usos, pode ser vista nesse enquadramento como disputas de políticas de justiça ou injustiça cognitiva.

Assim, nas aulas da disciplina "Currículo" - oferecida pelo grupo de pesquisa em conjunto, todo semestre, 60h/a, segundas-feiras à tarde embaixo do bondinho do Pão-de-Açúcar ${ }^{4}$, sendo uma atividade obrigatória para os graduandos em pedagogia e optatoria ${ }^{5}$ para as licenciaturas - nosso trabalho tem sido pautado na conversa como método de ensinaraprender e pesquisar. Utilizamos as escritas livres, ou escrivinhações (AUTOR, 2011), e valorizamos outras linguagens dispostos a enfrentar o poder silenciador da economia escriturística (CERTEAU, 1994, p. 221) alimentada

\footnotetext{
${ }^{4}$ O Pão-de-Açúcar é uma dupla de morros que fica na Urca. Ligados por bondinhos, é um dos cartões postais do Rio de Janeiro e recebeu esse nome por ter formato similar aos imensos torrões de açúcar que eram produzidos no Brasil colonial escravista.

${ }^{5}$ Quando uma disciplina optativa é a única que cabe na "grade" de horário tornando-se, de fato, obrigatória.
} 
também por práticas acadêmicas que reforçam alianças pouco saudáveis entre oralidade e escrita e leitura e escrita.

Para nós, escrever "nada tem a ver com significar, mas com agrimensar, cartografar, mesmo que sejam regiões ainda por vir.” (DELEUZE, GUATTARI, 1995a, p. 19). Acreditamos que descentramentos para o Sul nos ajudam a enfrentar o desafio de "ensinar a escrita a conversar com a oralidade" (COUTO, M. 2011, p. 103) estimulando os estudantes a contar, cantar, desenhar, costurar, escrever, narrar, analisar, representar seus selfies. Escrever, na aula de currículo, busca tecer outros conhecimentos com os conhecimentos do idioma, fazendo das escritas arquiteturas políticas de nós mesmos.

Nessa direção, vale entender que os currículos e as escritas são criados cotidianamente (OLIVEIRA, 2012) como uma conversa complicada (PINAR, 2012) e que por isso há a necessidade de ouvir o que os praticantes da vida cotidiana (CERTEAU, 1994) têm a dizer se queremos entender os conhecimentos como condição de existência na relação entre as pessoas e não como uma propriedade individual. $\mathrm{O}$ argumento utilizado aqui é de que currículos assim como escritas são conversas que falam tanto de quem conversa/escreve quanto do mundo e dos conhecimentos. Falam articulando sentidos de modo precário e fugaz num movimento arquitetônico de desconstrução e enredamento de si, do mundo e dos conhecimentos.

Uns e outros se desenvolvendo e desenvolvendo conhecimento em extensas e poderosas redes de contatos, comunicação e informações, não agindo somente enquanto consumidores, mas no uso que fazem do que é criado pela ciência e pela técnica, e imposto pelo capital, assumem sempre o lugar de criador, para muito além da passividade e da disciplina. (ALVES, 2001, p.116).

Nas aulas, conversando, fazendo com, conhecendo em redes na busca cotidiana de justiça cognitiva, desafiando a sociedade espetacular onde "os jornalistas e os mediocratas (como os psicanalistas na esfera privada) são o novo clero dessa alienação da natureza linguística do homem" (AGAMBEN, 2015, p. 81).

E, ao se perguntar se e como é possível "transmitir" o que foi sendo apreendido/aprendido, Alves desdobra o problema:

é preciso uma outra escrita para além da já aprendida. Há assim, uma outra escritura a aprender: aquela que talvez se expresse como múltiplas linguagens (de sons, de imagens, de toques, de cheiros etc) e que, talvez, não possa ser chamada mais de "escrita"; que não obedeça à linearidade de exposição, mas que teça, ao ser feita, uma rede de múltiplos, diferentes e diversos fios; que pergunte muito além de dar respostas; que duvide do próprio ato de afirmar, que diga e desdiga... (ALVES, 2008, p. 30-31) 
Numa escrita já aprendida, a ideia de uma Base traz a decifração prescritiva do resultado do conhecer. Há essa escrita já aprendida, que opera como máquina barulhenta ensurdecendo outras escritas porque não se recheia de experiência, desfaz do vivido, desvaloriza o oral em nome de uma economia escriturística da palavra. Escrita que busca fazer uma aula que seja entendida do modo igual pelos diferentes. A Base, em sua proposta de escrita e de conhecimento, argumentamos (AUTOR; PELLEGRINI, 2016, p. 8) produz a linearidade por meio da relação direta entre causa e efeito, esmagando outras possibilidades de temporalidades e espacialidades do conhecer. Considerar esse pensamento soa de máxima importância no momento em que a mordaças, projetos legislativos e políticas oficiais caçam palavras, temas e disciplinas expurgando as diferenças dos espaços escolares, entre outros. Com a crença de que nos cotidianos temos possibilidade de praticar políticas de escritas mais democráticas, com Agamben, e com a escrita de EA, admitimos que

A política contemporânea é esse experimentum linguae devastador, que desarticula e esvazia em todo planeta tradições e crenças, ideologias e religiões, identidades e comunidades. (AGAMBEN, 2015, p. 82)

Venho repetindo, ameaçada pelo controle curricular proposto pela Base e embalada pelos aprendizados com Certeau, Alves, Oliveira, Pinar e outros que toda aula é uma criação curricular inédita e única. Curricular, para nós, é fazer toda segunda-feira uma conversa complicada que conecta o mundo e as pessoas, REconhecendo as epistemologias diversas e tendo a diferença como princípio.

[O] reconhecimento não pode ser reduzido à formulação e à emissão de juízos sobre os outros. Indiscutivelmente, há situações éticas e legais em que esses juízos devem ser feitos. (...) Na verdade, o reconhecimento muitas vezes nos obriga a suspender o juízo para podermos apreender o outro. (BUTLER, 2015, p. 63).

Colecionando propostas e trabalhos finais, conversas de orientação por e-mail com a professora e a monitora, registros de escrivinhações e de conversas, listas de textos lidos e provasplatô ${ }^{6}$ selecionamos pistas para pensar as teoriaspráticas e narrativas de currículos, as conversas como epistemo-metodologia, os cotidianos nas escolas públicas, a democratização da democracia, as epistemologias do Sul e a formação de professores que são nossas apostas de pesquisa. Para isso, temos lido e conversado sobre pós-estruturalismo, democracia, relatos de formação de professores, o golpe institucional em 2016, o contexto internacional da reforma curricular que defende uma base

\footnotetext{
${ }^{6}$ A prova platô envolve dois momentos: a escrita em platôs em sala e a leitura comentada e enviada a todos. Ao final do curso, em sala, os estudantes escrevem sobre um assunto de seu interesse em um determinado período de tempo. Quando o tempo se esgota eles, logo em seguida, trocam suas escritas para que o outro possa continuar escrevendo, contudo a próxima escrita não precisa completar a anterior, podendo ser independente e seguindo os interesses que cada um teve nas conversas e leituras. Há atribuição individual e coletiva de nota.
} 
nacional $^{7}$, a IMpossibilidade de silenciar sobre gênero, as ocupações das escolas e universidades públicas em 2016, entre outros temas.

Em relação à escrita, tenho notado nesses semestres, que nunca se repetem mas aparentam repetição quando percebemos que nem todos estudantes podem relatar uma relação saudável com o que é considerado válido no mundo do conhecimento e das letras. Na busca de escritas autorais e que REconheçam cada estudante em seu conhecimento, por vezes, o trabalho final é o lugar de contar aquilo que a Universidade vem silenciando, nos modos fixos de ver/conhecer/escrever/ler o mundo, nos modos injustos de criar conhecimentos, na abdução da diferença nas políticas de escrita.

Deslizando nas escritas chama atenção o trabalho de um estudante que colou grau em agosto de 2017 dizendo que "aprendemos a negociar na diferença" para justificar o uso de beca por apenas parte da turma quando indagado se "não ficaria melhor todos estarem igualmente vestidos?" durante a formatura. Vitimado pelas políticas invisíveis de abdução da alteridade que vigem na produção da escrita certa conheci EA. Nos conta isso na proposta de trabalho final que dá o subtítulo desse artigo.

EA era formando da Licenciatura em Música quando matriculou-se na disciplina Currículo comigo. Contou-nos que começou a ler e escrever quando a maior parte de seus colegas universitários já tinha seis ou sete anos de contato com as letras e precisou quebrar armadilhas (COUTO, 2011), não só para lidar com uma história familiar que aponta no mínimo para a negligência do estado, mas também com as barreiras encontradas em sua trajetória acadêmica na universidade. Sim, na universidade púbica onde ingressou via concurso, mais especificamente na nona tentativa, em suposta condição de igualdade com todos que ali estão. Talvez, com muito mais vontade e gana que muitos. Certamente, permaneceu ali mais apoiado nas redes de solidariedade que teceu fora da universidade. No sentido que damos a Santos (2006) quando desinvisibilizamos os conhecimentos de EA valorizando sua trajetória e experiências vividas enxergando de outro modo a sua escrivinhação, podendo e querendo ver situações produzidas como invisíveis e, portanto, difíceis de ver/crer e que sugerem que a universidade é feita no mundo, mas não é feita de mundo (SANTOS, 2006, p. 138).

Produzido como incapaz de escrever bem pela linha desenhada nas práticas de escrita pelos conhecimentos validados nos espaçostempos da universidade, EA, relata,

\footnotetext{
7 “A Base Nacional Comum Curricular (BNCC) é um documento de caráter normativo que define o conjunto orgânico e progressivo de aprendizagens essenciais que todos os alunos devem desenvolver ao longo das etapas e modalidades da Educação Básica" (BNCC, 3a versão, 2017, p. 7).
} 
sempre fui muito humilhado a minha vida inteira por questões de não saber ler e quando aprendi a ler, não saber escrever direito como convém. Quando chego a universidade, sou humilhado por alguns professores que criticam com veemência minha escrita e português errado em vez de me ajudar a cuidar na deficiência. (EA, estudante, 2017.1) (sic)

EA criou nas conversas em sala de aula a possibilidade de dizer, e escrevinhar, sobre a importância que ele atribui à presença de sua biografia no conhecimento que ele elaborou em seu Trabalho de Conclusão de Curso (TCC). Por quê? Explica EA que "não tem como entender o que penso e como ajo se os leitores desse trabalho não identificarem a razão de alguns pensamentos e atitudes que tomei e combato em minha vida" (sic) sabedor de que "a experiência social em todo mundo é muito mais ampla e variada do que o que a tradição científica ou a filosofia ocidental conhece e considera importante" (SANTOS, 2004, p. 778).

Não surpreende que sua defesa tenha ficado restrita à sala de aula no império da academia que "faz da escrita sua própria lei” (CERTEAU, 2012a, p. 125). Império onde o docente é também súdito e defende o que o fragiliza. "É levado a reforçar o rigor da lei das fronteiras de um império do qual não está mais seguro" (p. 131). A diferença do mundo que aparece nas formas de escrita ameaça a academia e suas políticas e práticas de escrita. A diferença é política. Exatamente como recebi, copio abaixo parte do trabalho de EA onde ele conta porque é tão importante saber da história de sua vida que se inscreve em sua escrita. Como ele diz, saber de sua "história de vida, ou da falta que tenho das palavras" (sic) (EA, estudante, 2017.1).

Quando ${ }^{8}$ estava com 12 anos, sem escola, sem estudar, sem saber ler, sem cuidados primários necessários de uma fase de adolescência, e minhas irmãs viviam largadas pela rua e casa de vizinhos, minha mãe foi denunciada por maus tratos e abandono de incapazes. Então a partir daí eu e minhas irmãs fomos morar em uma instituição de menores. Inicialmente eu fui para a FIA do barreto, mas como eu não era menor infrator, fugi desse local pois fui ameaçado de morte um grupo que iria fugir e eu ouvi o plano, então procurei novamente o conselho tutelar e fui levado para a instituição que minhas irmãs estavam chamada de OSFA (OBRAS SOCIAIS FÉ E ALEGRIA) uma ong sustentada por holandeses.

Ao chegar a essa instituição fui logo matriculado em uma escola na antiga primeira série já com 13 anos. Também tinha aulas de música, artesanato, hortaliças, tapeçaria, teatro, vassouraria e outras terapias ocupacionais.

Aos 14 anos fiz um projeto de aceleração do governo cursando no mesmo ano a segunda, terceira e quarta série juntas. Aos 15 anos fiz o quinto ano normal.

\footnotetext{
${ }^{8} \mathrm{O}$ texto corrido e citações do trabalho final de EA segue em negrito por decisão da autora considerando a necessidade para construção do argumento do texto de manutenção da escrita original (sic) devido às suas características estéticas, históricas e de enfrentamento à norma culta.
} 
Com 16 anos fui fazer no bairro e Alcântara um supletivo onde cursei as seguintes séries em um ano, sexta, sétima e oitava série do ensino fundamental.

Com 17 fiz o primeiro ano normal, com 18 anos saí da instituição e fui morar na ilha cursando lá em uma escola estadual a noite o segundo ano do segundo grau. Com 19 anos fui morar na província e cursei o terceiro do ensino médio na escola Celestino da Silva na Rua do Lavradinho

19 anos fiz o primeiro vestibular pra música pegando a guarda da minha irmã mais nova

20 anos o segundo pegando a guarda da minha irmã mais velha que é "especial"

21 anos o terceiro

22 anos o quarto e todos eles na UFRJ

23 anos me casei então não prestei concurso

24 anos o quinto, agora já prestando THE para UFRJ e UNIRIO

25 anos o sexto para as duas

26 anos o sétimo para as duas

27 anos o oitavo para as duas

28 finalmente consegui passar para a Unirio realizando o sonho de cursar licenciatura em música.

Quando chego a universidade, já tinha tido a experiência de dar aula no projeto mais educação na escola Paulo Freyre na Maré (aos 23 anos) e na creche escola Sara Kaley (aos 20 anos). Entrei no curso de licenciatura em 2013.2 e em 2017.1 estou concluindo no oitavo período com 5 matérias restantes um curso que que pretendia ter 8 matérias por período, mas como tenho alguns problemas de saúde e durmo pouco, aproveito o tempo acordado para estudar e assim pude adiantar bastante o curso.

\section{QUEBRANDO ARMADILHAS}

Fazendo agora uma defesa já que pude mencionar nesse trabalho um pouco e resumidamente a minha história, como a citar o texto que tive na aula de currículo "quebrar armadilhas" que teve tudo a ver com minha história de vida, ou da falta que tenho das palavras. Na verdade não sei dizer o quanto vou escrever certo nesse trabalho.

A questão não é apenas do domínio de técnicas de decifração do alfabeto. Trata-se, sim, de possuirmos instrumentos para sermos felizes. E o segredo é estar disponível para que outras lógicas nos habitem, é visitarmos e sermos visitados por outras sensibilidades. É fácil sermos tolerantes com os que são diferentes. É um pouco mais difícil sermos solidários com os outros. Difícil é sermos outros, difícil mesmo é sermos os outros. (COUTO, 2009, p.54, do pdf)

Começo com essa citação do livro "E se o Obama Fosse Africano" pois sempre fui muito humilhado a minha vida inteira por questões de não saber ler e quando aprendi a ler, não saber escrever direito como convém. Quando chego a universidade, sou humilhado por alguns professores que criticam com veemência minha escrita e português errado em vez de me ajudar a cuidar na deficiência que tenho falta. "O desafio seria 
alfabetizar sem que a riqueza da oralidade fosse eliminada. O desafio seria ensinar a escrita a conversar com a oralidade" (COUTO, 2009, pág 55, do pdf)

Quando começo a ler aos 13 anos, o conta como experiência de vida pra mim até então é a oralidade, isso como me comunicava, como o que usava o dia inteiro. Hoje por estar em uma academia tenho que ter uma boa escrita, sendo que me faltou uma certa experiência no uso dela já que tive pouco tempo dentro da escola como se pode gostar nessa breve história resumida que pude contar nesse trabalho.

Falamos em ler e pensamos apenas nos livros, nos textos escritos. O senso comum diz que lemos apenas palavras. Mas a ideia de leitura aplica-se a um vasto universo. Nós lemos emoções nos rostos, lemos os sinais climáticos nas nuvens, lemos o chão, lemos o Mundo, lemos a Vida. Tudo pode ser página. Depende apenas da intenção de descoberta do nosso olhar. Queixamo-nos de que as pessoas não leem livros. Mas o déficit de leitura é muito mais geral. Não sabemos ler o mundo, não lemos os outros. (COUTO, 2009, pág 55, do pdf)

Essa é a passagem do texto que mais me chama a atenção por eu ter uma identidade enorme com ela. Aprendi em minha vida, até como defesa, a ler "pessoas" ler atitudes pra ver se não iriam mentir pra mim de novo, se não iriam me enganar com palavras ou atitudes violentas ou preconceituosas. (sic)

O texto em destaque alonga-se por sete páginas com espaço simples. Escrito pelo celular já que ele NUNCA teve um computador, EA nos possibilita fazer múltiplas leituras, e, nos faz também ler a nós mesmos, nossos ranços e preconceitos com a escrita dita errada ou, ruim.

Volte. Leia novamente, desta vez, em voz alta. Olhe além das ausências de maiúsculas, conectores, pontuação... Perceba a sonoridade da escrita. Veja como está registrada graficamente. A escrita de EA traz as marcas estéticas da música, da rua, da oralidade, de seu corpo negro e pobre, de sua religiosidade radiante. Graficamente, metricamente, ortograficamente, as marcas e presenças na escrita de EA refutam as teses de erro e ignorância sugerindo possibilidades visíveis e audíveis de se ler, entender, aprenderensinar nascom as palavras a injustiça cognitiva social, racial ao mesmo tempo que lemos solidariedade e esperança.

A escrita de EA não é trazida neste artigo apenas como uma alternativa políticoepistemológica ao modo dominante ou culto de escrever, embora seja. Sua escrita também marca outra política, com uma paragrafação que altera o tempo de leitura, que aliás, desvia o tempo da leitura usando (erroneamente e certeaunianamente) a paragrafação. De modo IMprevisto na norma culta, os parágrafos de EA marcam o fracasso no acesso. A repetição do Enem por nove vezes. Rejeição, humilhação, solidariedade, orgulho, sonho. Tudo encarnado nas palavras que a norma, incestuosa, pode corrigir, mas não silencia.

À época licenciando em música, EA alega padecer de "falta de palavras", além de "não ter uma boa escrita". Mas ele sabe que o problema é outro: "não saber escrever direito como convém". EA aprendeu a identificar quais são as regras de um jogo antes de jogá-lo. As tessituras de redes de solidariedade marcam sua biografia e sua escrita. Não é ausência da regra, "mas a 
irresponsabilidade radical da palavra" (DERRIDA, 2014, p.259). Se uma "regra de gramática é um marcador de poder, antes de ser um marcador sintático" (DELEUZE, GATTARI, 1995b, p. 13) as escritas de EA estão na disputa desse poder, num movimento de impoder.

A generosidade da inspiração, a irrupção positiva de uma palavra que vem não sei donde, acerca da qual sei, se for Antonin Artaud, que não sei donde vem nem quem fala, essa fecundidade do outro sopro é o impoder: não a ausência, mas a irresponsabilidade radical da palavra, a irresponsabilidade como poder e origem da palavra. (DERRIDA, 2014, p.259)

Nesse movimento, suas escritas nos desafiam a compreendê-lo para além da norma culta e, com ritmo, repete numa escrita, poderosa estética e graficamente suas tentativas de acessar o espaço do ensino superior. As escritas, nas palavras narradas por EA, nos sufocam, pois, desinvisibilizam práticas e políticas de injustiça não tão incomuns no meio acadêmico. A universidade vista aqui como máquina escriturística (CERTEAU, 1994, p. 221) que silencia com suas normas e valores eurocentrados e se torna, também, na desobediência e no protesto, o espaçotempo que DESamordaça uma voz de tradução da injustiça.

O suplemento de leitura ou de escritura deve ser rigorosamente prescrito, mas pela necessidade de um jogo, signo ao qual é preciso outorgar o sistema de todos os seus poderes. (DERRIDA, 2005, p. 8)

EA chega à universidade, mas não está entre os “menos de 30\% de estudantes que saíram do ensino médio dominando as regras da língua portuguesa" ". Numa defesa enfurecida da norma, reformistas e reformas educacionais vociferam que a solução para o problema seria "uniformizar procedimentos educacionais em todo país" (idem). Reduzindo vidas a números, os reformistas informam, defendendo uma tal idade certa para aprender a ler e bradam que "no Paraná apenas 5\% das crianças não estão alfabetizadas aos 8 anos"(idem, grifo nossos). EA era apenas. Aprendeu a ler com 13 anos, sendo esta sua idade certa. Teve cinco dos 12 anos de escolaridade. Mas não bastava isso, a universidade, com "alergia à diversidade interna" (CERTEAU, 2012a, p. 124), viria fazer um "papel de polícia" (p. 104) da língua culta "transformando em gargalo a passagem entre o presente e o futuro dos jovens" (p. 105). O que poderia ser, de fato, surpreendente nessa história é o tempo de formatura de EA. Mas não é. Ele é pai, precisa trabalhar e aprendeu a dormir pouco.

Entre números, leis e normas EA é despido de sua condição humana, humilhado. Com Santos traduzimos a injustiça da construção de direitos humanos que tratam EA como objeto do discurso de direitos e não como sujeito desses direitos (SANTOS, 2013, p. 13). A realização de seu

\footnotetext{
${ }^{9}$ Disponível em: <http://www.todospelaeducacao.org.br/educacao-na-midia/indice/24832/editorial-30-chegam-aos-8anos-sem-alfabetizacao-no-para/; e http://g1.globo.com/hora1/noticia/2015/07/alunos-estao-saindo-da-escola-sem-saber -direito-matematica-e-portugues.html>.
} 
direito de ir à escola, à universidade e de aprender se fez na negação de seu direito de ser. Ambos explicam.

\begin{abstract}
A hegemonia global dos direitos humanos como linguagem de dignidade humana é hoje incontestável. No entanto, esta hegemonia convive com uma realidade perturbadora: A grande maioria da população mundial não é sujeito dos direitos humanos. É objeto de discursos de direitos humanos. (SANTOS, 2013, p. 13).
\end{abstract}

Término essa parte fazendo a seguinte citação, "a mais perigosa armadilha é aquela que possui a aparência de uma ferramenta de emancipação. Uma dessas ciladas é a ideia de que nós, seres humanos, possuímos uma identidade essencial" ( COUTO, 2009, pág 53, do pdf). A escrita pra mim nunca foi um lugar de emancipação, e sim de desconforto, insegurança, incredulidade e principalmente muita falta de compreensão. Sempre tive uma identidade ( mesmo como menino de rua) mesmo não tendo o domínio da escrita, e querem me fazer acreditar que a escrita convencional é a identidade mais importante é libertadora para o se humano. Não é mesmo!!! (sic)

Num uso astuto, oportuno e porque não otimista de Couto, "já que o pessimismo é um luxo para os ricos" (2011, p. 28) EA se apresenta como produtor e não consumidor da (sua) história (p. 34) e luta para "desarmadilhar o mundo para que ele seja mais nosso e mais solidário" (p. 95). E, praticante do cotidiano, consumidor-criador de cultura e usuário das artes do fraco perambula pelos sistemas impostos e "não se faz notar com produtos próprios, mas com maneiras de empregar os produtos impostos por uma ordem dominante" (CERTEAU, 1994, p. 39). Esta, racionalizada, expansionista, centralizadora, barulhenta, totalitária, "não deixa aos consumidores um lugar por onde possam marcar o que fazem com os produtos" (idem).

Mas, tornando visível o que se produziu como inexistente, as "táticas tão negadas pela epistemologia da ciência" (CERTEAU, 1994, p. 52), as marcas de EA aparecem em suas escritas. E, embora ele diga, como "uma arte sutil de locatários" (p. 50) não saber o quanto iria "escrever certo nesse trabalho" produz a "golpes" “alianças microscópicas multiformes e inumeráveis” (p. 52).

Essas maneiras de se reapropriar do sistema produzido, criações de consumidores, visam uma terapêtica de socialidades deterioradas, e usam técnicas de reemprego onde se podem reconhecer os procedimentos das práticas cotidianas. Deve-se então elaborar uma política dessas astúcias. (CERTEAU, 1994, p. 52).

E é em busca de políticas das astúcias cotidianas que andamos. Políticas em que as escolas públicas e seus professores e estudantes pobres, negros, vyados, beechas, sapatões, travas, monas, manas, mulheres, feminazis, trans, cis, candomblecistas, ciganos, crentes, todos em sua diferença, diversidade e adversidades não sejam o problema. Ainda EA, mina o estabelecido e problematiza a 
formação universitária quando explica o tema de seu TCC (Trabalho de Conclusão de Curso, do qual o trabalho final de currículo seria um pós-escrito, ou um making-off como acordamos chamar).

Vi o despreparo de professores para lidar com o cotidiano de uma escola pública no Rio de Janeiro e exponho a problemática que traz a universidade para esse assunto em formar educadores musicais que não sabem lidar com a cultura, com a situação social e com a realidade do aluno (sic).

Parafraseando a famosa sentença de Boaventura de Sousa Santos (2004), defendo que EA têm o direito de ter sua escrita reconhecida com igualdade quando a escrever fora da norma o inferioriza. Também, EA, tem o direito a ser diferente quando a obrigação de escrever dentro da norma o descaracteriza. "As pessoas querem ser iguais, mas querem ser respeitadas em suas diferenças. Ou seja, querem participar, mas querem também que suas diferenças sejam reconhecidas e respeitadas" (p. 458).

\section{EM BUSCA DAS POLÍTICAS DAS ASTÚCIAS}

Decifrando, explicando, significando e interpretando, o pensamento abissal (SANTOS, 2010), ícone de injustiça cognitiva e expressão incestuosa do paradigma científico hegemônico, que cria simulacros com seus pensamentos, que se assumem realidade (DERRIDA, 2014, p.40), se tornam realidades e ofuscam o ordinário (CERTEAU, 1994). Enfrentando máquinas conceituais barulhentas que tentam, pela explicação que faz exemplo de entendimento de verdade, nos ensurdecer para os sussurros dos praticantes. Desinvisibilizando as produções impertinentes que não cessam de acontecer e que se fazem ativamente. Criações astutas dos homens ordinários que bricolam no impoder suas possibilidades de ser.

Assim vi o trabalho de EA.

Defendo, junto ao meu grupo de pesquisa e trabalho, com suporte num currículo sem fundamentos (LOPES, 2015), criado cotidianamente como conversas complicadas (PINAR, 2012) e num movimento de impoder que o trabalho aqui exposto (que estava ainda em fase de elaboração) é criativo, autônomo, tendo trazido de modo muito contundente a teoria. EA, o autor, o elaborou a partir das suas experiências pessoais e reflexões sobre currículos. Penso, que, sobretudo, comunica sobre nós, sobre conhecimento, sobre os eus, e o mundo. Participa na diferença, mesmo quando as negociações parecem uma máquina de produzir silêncios e invisibilizar as diferenças.

Sabemos, no contexto atual, o quão relevante é enfrentar as hierarquias e injustiças nos cotidianos, com políticas de astúcia (CERTEAU, 1994). Sabemos também qual é o papel que nos impõe o lugar de teóricos do currículo diante das políticas de abdução da diferença dos currículos e do tratamento da palavra como coisa. 
A teoria do currículo diz respeito à descoberta e à articulação, para si e para os outros, do significado educacional das disciplinas escolares, para o eu e para a sociedade, em momento histórico em constante transformação. Em consequência, a teoria do currículo rejeita a atual reforma do ensino "inspirada no mundo dos negócios", com sua ênfase em notas de provas padronizadas, análogos acadêmicos do produto final das empresas, isto é, "lucros". (PINAR, 2008, p. 141)

Já argumentamos que professores e estudantes são tornados ruins quando exigimos que produzam resultados iguais (PINAR; 2012; AUTOR; 2014), pois “é impossível encontrar duas escolas iguais" (EZPELETA; ROCKWELL;1989, p. 58), sendo assim desvalorizados, demonizados, esculachados em pesquisas, na mídia e pela sociedade em geral. Nesse sentido, as (im)possibilidades (ontológica; epistemológica) dos professores de darem as mesmas aulas, seguirem manuais ou treinarem seus estudantes para darem respostas padronizadas são percebidas como (in)capacidade ou (des)preparo (AUTOR, 2014) bem como fracassados são os estudantes que não sucedem como previsto. Isso tem baseado meus argumentos contra políticas governamentais de unificação curricular, mas é preciso reconhecer o poder que as práticas e políticas cotidianas têm de subverter, inventar, burlar ou retroalimentar as redes, agências e estruturas de poder.

Nosso investimento políticoepistemológico no re-conhecimento do trabalho docente como criação intelectual e no direito do estudante a aprender na diferença e com respeito a ela, reside também no investimento teórico na "refutação das teses comuns sobre a passividade dos consumidores, e a massificação dos comportamentos" (GIARD, 1994, p. 27) e nos impõe a pensar os conhecimentos sempre no plural, considerando sua fabricação cotidiana e suas incontáveis possibilidades de usos (CERTEAU, 1994, p. 39). A atividade silenciosa que é a leitura "parece aliás constituir o ponto máximo da passividade que caracterizaria o consumidor" (p. 49) no contexto escriturístico em que o oral "não contribui para o progresso" (p. 224) e que, nos três últimos séculos, vincula à iniciação na sociedade capitalista à prática da escrita (p. 227), sendo preciso "sentir os efeitos inquietantes de um tão prodigioso avanço para que suspeitássemos ser a formação da criança moderna uma prática escriturística" (idem). Mas Certeau adverte que o leitor será sempre impertinente (p. 272), escrevendo e inscrevendo outros textos com suas leituras e escritas, pois, como vai soar diferente, vale repetir.

[O]nde o aparelho científico (o nosso) é levado a partilhar a ilusão dos poderes de que é necessariamente solidário, isto é, supor as multidões transformadas pelas conquistas e vitórias de uma produção expansionista, é sempre bom recordar que não se deve tomar os outros por idiotas. (CERTEAU, 1994, p. 273). 


\section{REFERÊNCIAS}

ALVES, N. Sobre movimentos das pesquisas nos/dos/com os cotidianos. In: OLIVEIRA, I. B.; ALVES, N. A Pesquisa nos/dos/com os cotidianos das escolas sobre redes de saberes. Rio de Janeiro: DP et Alii, 2008.

ALVES, N.; GARCIA, R. L.; O sentido da Escola, Garcia. (Orgs.) 3. ed. Rio de Janeiro: DP\&A, 2001.

AGAMBEN, G. Meios sem fim: Notas sobre a política. Belo Horizonte: Autêntica, 2015.

BUTLER, Judith. Relatar a si mesmo: crítica da violência ética. Trad.: Rogério Bettoni. Belo Horizonte: Autêntica, 2015.

BRASIL. Lei 9.394, de 20 de dezembro de 1996. Estabelece as diretrizes e bases da educação nacional. Diário Oficial da União. Brasília: Poder Legislativo, 23 dez. 1996, sec. I, n. 248, p. 27.833.

Base Nacional Comum Curricular. Brasília: MEC/SEB. 2017.

CERTEAU, Michel. A Cultura no Plural. São Paulo: Papirus, 2012a .

História e psicanalise: entre ciência e ficção. Belo Horizonte: Autêntica, 2012b.

A invenção do cotidiano: artes de fazer. Tradução de Ephraim Ferreira Alves. Petrópolis: Vozes, 1994.

COUTO, Mia. E se Obama fosse africano? e outras interinvenções: São Paulo: Cia das Letras, 2011.

DELEUZE, Gilles; GUATTARI, Félix; Mil platôs: capitalismo e esquizofrenia. Trad.: Aurélio Guerra Neto e Célia Pinto Costa. Rio de janeiro: Ed. 34, 1995b. vol. 01.

; GUATTARI, Félix; Mil platôs: capitalismo e esquizofrenia. Trad.: Aurélio Guerra Neto e Célia Pinto Costa. Rio de janeiro: Ed. 34, 1995'a vol. 2.

DERRIDA, J. A escritura e a diferença. São Paulo: Perspectiva, 2014.

DERRIDA, J. A farmácia de Platão. São Paulo: Iluminuras, 2005.

EZPELETA, J.; ROCKWELL, E. Pesquisa Participante. São Paulo: Cortez, 1989.

GIARD, L. História de uma pesquisa. In: CERTEAU, M. de. A invenção do cotidiano: 1, Artes de fazer. Petrópolis: Vozes, 1994.

LOPES, A. C. Por um currículo sem fundamentos. Linhas Críticas, Brasília, v. 21, n. 45, p.445-466, ago. 2015.

MACEDO, E. Base nacional curricular comum: a falsa oposição entre conhecimento para fazer algo e conhecimento em si. Educação em Revista, Belo Horizonte, vol.32, n.2, p.45-68, 2016.

OLIVEIRA, I.B. O Currículo como criação cotidiana. Petrópolis: DP et Alii, 2012.

PINAR, W. What is Curriculum Theory. Second Edition, NY: Routledge, 2012.

A equivocada educação do público nos Estados Unidos. In: GARCIA, R.L. MOREIRA, A.F.B. (Orgs.). Currículo na Contemporaneidade: incertezas e desafios. São Paulo: Cortez, 2008.

Autobiography, Politics and Sexuality: Essays in Curriculum Theory, 1972-1992. NY: Peter Lang, 1994.

SANTOS, B. S. Se Deus fosse um activista dos direitos humanos. Coimbra: Ed. Almedina, 2013.

; MENESES, M. P. (Orgs.). Epistemologias do Sul. São Paulo: Editora Cortez, 2010.

; Para além do pensamento abissal: das linhas globais a uma ecologia de saberes. Revista Crítica de Ciências Sociais, 78, p. 3-46, out. 2007.

SANTOS, B. S.; Ecologia de saberes. In: SANTOS, B. S. A gramática do tempo: para uma nova cultura política. São Paulo: Cortez, 2006.

(Orgs); Conhecimento prudente para uma vida decente: um discurso sobre as ciências revisitado: São Paulo: Cortez, 2004.

Crítica da razão indolente: contra o desperdício da experiência. São Paulo: Cortez, 2000.

SÜSSEKIND, M. L.; PELLEGRINI, R. A escrita nunca escrita" ou por que (re)afirmamos nossa contrariedade à Base Comum. In: FRANGELlA, R.C.P. (Org.). Currículo, formação e avaliação: redes de pesquisas em negociação. Curitiba: CRV, 2016. 
As (im)possibilidades de uma base comum nacional. Revista e-Curriculum, São Paulo, v. 12, n. 03; Out. 2014. Disponível em https://revistas.pucsp.br/index.php/curriculum/article/viewFile/21667/15917.

O Estágio como entrelugar nos relatos de formação. In: ; GARCIA, A. (Orgs) Universidade-Escola:

Diálogo e Formação de Professores. Petrópolis: De Petrus et Alii; RJ: FAPERJ, 2011.

\section{RESUMO}

Discute políticas consideradas não oficiais, disputas e suas implicações em relação ao que acontece nas salas de aula. Numa abordagem epistemológica do Sul e praticando uma sociologia das ausências, o texto objetiva desconstruir a ideia de escrita boa e correta a partir do trabalho de fim de curso de um estudante pensando a língua como armadilha incestuosa para as articulações precárias nas criações curriculares cotidianas. $\mathrm{O}$ artigo propõe contextualizar o papel do uso da escrita correta no espaçotempo da universidade e da formação de professores como fluxos e políticas cotidianas, como práticas de podere em busca de políticas de astúcias.

Palavras-chave: Currículos, políticas, estudos dos cotidianos.

\section{WHAT HAPPENED IN THE CLASSROOM? POLICIES, CURRICULUM AND WRITINGS WITHIN EVERYDAY LIFE TEACHER'S EDUCATION IN A PUBLIC UNIVERSITY, BRAZIL. ABSTRACT}

Discusses policies considered unofficial, disputes and their implications in relation to what happens in classrooms. In an epistemological approach of the South and practicing a sociology of absences, the text aims to deconstruct the idea of good and correct writing from the SA of a student and advocates the language as an incestuous trap for precarious negotiations in everyday life curricular creations. The article proposes to contextualize the role of the use of correct writing in university space and time and teacher's education as everyday life flows and policies, as practices of power and in search of politics of artfulness.

Keywords: Curricula, policies, everyday life studies.

\section{¿QUÉ SUCEDIÓ EN LA CLASE? POLÍTICAS, CURRÍCULOS Y ESCRITURAS EN LOS COTIDIANOS DE LA FORMACIÓN DE PROFESORES EN UNIVERSIDAD PÚBLICA RESUMEN}

Discute políticas consideradas no oficiales, las disputas y sus implicaciones en relación a lo que sucede en las aulas. En un abordaje epistemológico del Sur y practicando una sociología de las ausencias, el texto objetiva deconstruir la idea de escritura buena y correcta a partir del trabajo de fin de curso de un estudiante pensando la lengua como trampa incestuosa para las articulaciones precarias en las creaciones curriculares cotidianas. El artículo propone contextualizar el papel del uso de la escritura correcta en el espacio de la universidad y de la formación de profesores como flujos y políticas cotidianas, como prácticas de poder y en busca de políticas de astucias.

Palabras-clave: Currículos, políticas, estudios de los cotidianos. 